\title{
Nanoscale modification of porous gelatin scaffolds with chondroitin sulfate for corneal stromal tissue engineering
}

This article was published in the following Dove Press journal:

International Journal of Nanomedicine

22 February 2012

Number of times this article has been viewed

\section{Jui-Yang Lai* \\ Ya-Ting Li* \\ Ching-Hsien Cho \\ Ting-Chun Yu}

Institute of Biochemical and Biomedical Engineering,

Chang Gung University, Taoyuan,

Taiwan, Republic of China

*These authors contributed equally to this work
Correspondence: Jui-Yang Lai Institute of Biochemical and Biomedical Engineering, Chang Gung University, 259 Wen-Hwa Ist Road,

Kwei-Shan, Taoyuan, Taiwan 33302,

Republic of China

Tel +886 32 2II 8800 ext 3598

$\mathrm{Fax}+88632118668$

Email jylai@mail.cgu.edu.tw
Abstract: Recent studies reflect the importance of using naturally occurring biopolymers as three-dimensional corneal keratocyte scaffolds and suggest that the porous structure of gelatin materials may play an important role in controlling nutrient uptake. In the current study, the authors further consider the application of carbodiimide cross-linked porous gelatin as an alternative to collagen for corneal stromal tissue engineering. The authors developed corneal keratocyte scaffolds by nanoscale modification of porous gelatin materials with chondroitin sulfate (CS) using carbodiimide chemistry. Scanning electron microscopy/energy dispersive $\mathrm{X}$-ray spectroscopy and Fourier transform infrared spectroscopy showed that the amount of covalently incorporated polysaccharide was significantly increased when the CS concentration was increased from $0 \%$ to $1.25 \%(\mathrm{w} / \mathrm{v})$. In addition, as demonstrated by dimethylmethylene blue assays, the CS content in these samples was in the range of $0.078-0.149 \mathrm{nmol}$ per $10 \mathrm{mg}$ scaffold. When compared with their counterparts without CS treatment, various CS-modified porous gelatin membranes exhibited higher levels of water content, light transmittance, and amount of permeated nutrients but possessed lower Young's modulus and resistance against protease digestion. The hydrophilic and mechanical properties of scaffolds modified with $0.25 \% \mathrm{CS}$ were comparable with those of native corneas. The samples from this group were biocompatible with the rabbit corneal keratocytes and showed enhanced proliferative and biosynthetic capacity of cultured cells. In summary, the authors found that the nanoscale-level modification has influence on the characteristics and cell-material interactions of CS-containing gelatin hydrogels. Porous membranes with a CS content of $0.112 \pm 0.003 \mathrm{nmol}$ per $10 \mathrm{mg}$ scaffold may hold potential for use in corneal stromal tissue engineering.

Keywords: corneal keratocyte, carbodiimide chemistry, porous gelatin membranes, stroma

\section{Introduction}

Penetrating keratoplasty is the standard treatment for restoration of vision in patients with Stevens-Johnson syndrome, chemical/thermal burns, ocular cicatricial pemphigoid, corneal ulcers, pseudophakic bullous keratopathy, and Fuchs' endothelial dystrophy. However, the donor shortage has led to the expansion of research in the field of corneal regenerative medicine. ${ }^{1}$ The stroma, which consists of keratocytes and extracellular matrix (ECM) components such as collagen and glycosaminoglycans (GAGs), is the major structural element of the cornea. Therefore, collagenous biomaterials have been extensively investigated for tissue engineering of corneal stroma. ${ }^{2-4}$ These studies reflect the importance of using naturally occurring biopolymers as three-dimensional corneal keratocyte scaffolds. 
Gelatin is obtained by the thermal, chemical, or physical denaturation of collagen. As a protein-based biomaterial, gelatin is inexpensive and has no antigenicity under physiological conditions. Using the anterior chamber of a rabbit eye as a model, the authors have demonstrated the ocular biocompatibility of gelatin hydrogels. ${ }^{5}$ Because of their bioadhesiveness and biodegradability, gelatin carriers are found to temporarily hold the tissue-engineered corneal endothelial cell sheets in the proper position for graft-host integration. ${ }^{6,7}$ More recently, the 1-ethyl-3-(3-dimethylaminopropyl) carbodiimide hydrochloride (EDC) cross-linked porous gelatin discs have been designed to improve aqueous humor circulation and minimize adverse biological effect. ${ }^{8}$ The results suggest that the porous structure of gelatin materials may play an important role in controlling nutrient uptake. In this study, the authors further consider the application of carbodiimide cross-linked porous gelatin as an alternative to collagen for corneal stromal tissue engineering.

GAG is known to possess many biological activities such as interaction with growth factors and regulation of cell proliferation and differentiation. It has been documented that the corneal stroma contains on average GAG $0.0103 \mathrm{~g}$ per $\mathrm{cm}^{3} .{ }^{9}$ A study from Liu et $\mathrm{al}^{10}$ demonstrated that the decrease in the refractive index of EDC cross-linked collagen hydrogels is presumably due to the absence of GAG chains. Additionally, GAGs are thought to influence corneal hydration through interactions with collagen matrices. ${ }^{11}$ Although GAG is able to enhance hydrodynamic characteristics, the water sorption may simultaneously decrease the mechanical stability of biomaterial scaffolds. It is highly desirable to introduce the optimal amount of GAG into cross-linked porous gelatin membranes.

Chondroitin sulfate (CS) is a linear anionic polysaccharide composed of repeating disaccharide units of D-glucuronic acid and $N$-acetyl-D-galactosamine. It is one of the two major classes of GAG side chains in the corneal stroma and it is attached to serine residues on the core protein. ${ }^{12}$ In essence, CS has a molecular mass of $20-60 \mathrm{kDa}$ and contains free carboxylic acid groups available for carbodiimide-mediated modification. ${ }^{13}$ Hence, in this study, to fabricate the CS-modified porous gelatin scaffolds, the EDC was used to activate the free carboxyl groups of CS molecules for subsequent reaction with the remaining free amino groups of cross-linked gelatin molecules. The method based on covalent binding of polysaccharide to gelatin may offer the advantage of extending the in vivo residence time of CS to allow for better modulation of bioactivity of corneal keratocytes over that based on blending. To the authors' knowledge, the influence of nanoscale modification of gelatin with CS on the characteristics of corneal keratocyte scaffolds is yet to be investigated. Various CS-modified gelatin membranes were characterized by scanning electron microscopy (SEM), energy dispersive X-ray (EDS) and Fourier transform infrared (FTIR) spectroscopy, and dimethylmethylene blue (DMMB) assays. Then water content and light transmission measurements, mechanical and in vitro degradation tests, and glucose permeation and in vitro biocompatibility studies were performed to examine the relationship between CS levels and scaffold functionality. Cell-material interaction was also analyzed by monitoring the cell proliferation and morphology, as well as ECM production.

\section{Materials and methods \\ Materials}

Gelatin (type A, from porcine skin, 300 Bloom), chondroitin4-sulfate (type A, from bovine trachea), EDC, ninhydrin reagent, collagenase (type I Clostridium histolyticum, EC 3.4.24.3), Ehrlich's aldehyde reagent, and glutaraldehyde were purchased from Sigma-Aldrich (St Louis, MO). $N$-hydroxysuccinimide (NHS) was supplied by Acros Organics (Geel, Belgium). Deionized water used was purified with a Milli- $Q^{\circledR}$ system (Millipore, Bedford, MA). DMMB was purchased from Serva Feinbiochemica $\mathrm{GmbH}$ (Heidelberg, Germany). Balanced salt solution (BSS, pH 7.4) was obtained from Alcon Laboratories (Fort Worth, TX). Phosphate-buffered saline (PBS, pH 7.4) was acquired from Biochrom (Berlin, Germany). Dispase type II was obtained from Roche Diagnostics (Indianapolis, IN). Medium 199, gentamicin, 1:1 mixture of Dulbecco's modified Eagle's medium and Ham's F-12 medium (DMEM/F12), trypsinethylenediaminetetraacetic acid, and TRIzol ${ }^{\circledR}$ reagent were purchased from Gibco-BRL (Grand Island, NY). Fetal bovine serum (FBS) and the antibiotic/antimycotic (A/A) solution (penicillin 10,000 U/mL, streptomycin $10 \mathrm{mg} / \mathrm{mL}$, and amphotericin B $25 \mu \mathrm{g} / \mathrm{mL}$ ) were obtained from Biological Industries (Kibbutz Beit Haemek, Israel). All the other chemicals were of reagent grade and were used as received without further purification.

\section{Preparation of cross-linked porous gelatin scaffolds}

The cross-linked porous gelatin membranes were fabricated according to a previously published method. ${ }^{8}$ In brief, an aqueous solution of $10 \%(\mathrm{w} / \mathrm{v})$ gelatin was obtained by dissolution of gelatin powder in deionized water at $40^{\circ} \mathrm{C}$. The resulting solution was then poured into a polystyrene 
planar mold ( $5 \times 5 \mathrm{~cm}^{2}, 1.5 \mathrm{~cm}$ depth), subjected to freezing at $-80^{\circ} \mathrm{C}$ for 24 hours, and lyophilized at $-55^{\circ} \mathrm{C}$ for 2 days. All the prepared gelatin sheets were cross-linked by directly immersing the samples in an ethanol-water mixture (8:2, v/v; pH 4.75) containing EDC $50 \mathrm{mmol} / \mathrm{L}$ and NHS $10 \mathrm{mmol} / \mathrm{L}$. The cross-linking reaction was allowed to proceed at $25^{\circ} \mathrm{C}$ for 1.5-96 hours, and the treated samples were washed thoroughly with deionized water to remove excess EDC and urea by-product. Using a $7 \mathrm{~mm}$ diameter corneal trephine device, the gelatin sheets were cut out to obtain porous membrane scaffolds (approximately $100 \mu \mathrm{m}$ in thickness).

The ninhydrin assay was used to determine the amount of free amino groups of the chemically cross-linked gelatin samples. ${ }^{14}$ Following reaction with ninhydrin, the optical absorbance of the test solution was recorded with an ultraviolet-visible spectrophotometer (Evolution 300; Thermo Scientific, Waltham, MA) at $570 \mathrm{~nm}$, using glycine at various known concentrations as standard. The amount of free amino groups in the material before $\left(C_{\mathrm{i}}\right)$ and after $\left(C_{\mathrm{f}}\right)$ cross-linking is proportional to the optical absorbance of the solution. The extent of cross-linking of the gelatin scaffolds was calculated as cross-linking index $(\%)=\left(\left(C_{\mathrm{i}}-C_{\mathrm{f}}\right) / C_{\mathrm{i}}\right) \times 100$. Results were averaged on five independent runs.

\section{Modification of porous gelatin scaffolds with CS}

After EDC/NHS cross-linking at $25^{\circ} \mathrm{C}$ for 12 hours, the porous gelatin membrane scaffolds $(10 \mathrm{mg})$ were again immersed in an ethanol-water mixture $(8: 2, \mathrm{v} / \mathrm{v} ; \mathrm{pH} 4.75)$ containing EDC $10 \mathrm{mmol} / \mathrm{L}$, NHS $2 \mathrm{mmol} / \mathrm{L}$, and $0 \%-1.25 \%$ $(\mathrm{w} / \mathrm{v}) \mathrm{CS}$. The reaction proceeded for 24 hours under gentle shaking. To remove ionically bound CS, the treated samples were further washed with sodium chloride $500 \mathrm{mmol} / \mathrm{L}$, followed by washing with deionized water. The porous gelatin scaffolds were divided into four groups, depending on the amount of CS used $(0 \%, 0.05 \%, 0.25 \%$, or $1.25 \%$ $(\mathrm{w} / \mathrm{v})$ ), and were labeled accordingly: GCS000, GCS005, GCS025, and GCS125.

\section{Scaffold characterizations}

The samples were observed under a scanning electron microscope (S-3000 N; Hitachi, Tokyo, Japan) and analyzed with an energy dispersive X-ray spectroscope (Oxford Instruments, Concord, MA). ${ }^{15}$ Small pieces of the membrane scaffolds were cut off and mounted onto stubs using double-sided adhesive tape. The cross-section morphology of the samples was studied using a scanning electron microscope with an accelerating voltage of $20 \mathrm{kV}$. Twenty different pores were randomly selected, and the average pore diameters were calculated. Results were averaged on three independent runs. The elemental distribution was determined using X-ray elemental mapping. The solvent displacement method was used for porosity measurements. Each gelatin scaffold was first dried to a constant weight $\left(W_{\mathrm{i}}\right)$ in vacuo. The test samples were immersed in absolute ethanol overnight, blotted with tissue paper to remove excess ethanol on the surface, and weighed $\left(W_{\mathrm{f}}\right)$ immediately. The porosity $(\%)$ was calculated as $\left(\left(W_{\mathrm{f}}-W_{\mathrm{i}}\right) / V \rho\right) \times 100$, where $V$ is the volume of the hydrogel scaffold and $\rho$ is the density of absolute ethanol. Results were averaged on five independent runs.

The FTIR spectroscopy of various samples was performed using a FT-730 ATR-FTIR spectrophotometer (Horiba, Kyoto, Japan) according to a previously published method. ${ }^{16}$ The spectra were recorded between 3700 and $900 \mathrm{~cm}^{-1}$, with a resolution of $8 \mathrm{~cm}^{-1}$. The data were analyzed using FTIR spectrum software (Horiba) to obtain quantitative peak information. The results were the average of three independent experiments.

The CS content of various modified gelatin scaffolds was determined by DMMB assay. After hydrolysis of membranes with hydrogen chloride $6 \mathrm{~N}$ at $105^{\circ} \mathrm{C}$ for 6 hours, the samples were mixed with DMMB reagent solution (sodium chloride $40 \mathrm{mmol} / \mathrm{L}$; glycine $40 \mathrm{mmol} / \mathrm{L}$; DMMB $46 \mu \mathrm{mol} / \mathrm{L}, \mathrm{pH} 3.0$ ). The absorbance was read at $525 \mathrm{~nm}$, using a spectrophotometer (Multiskan ${ }^{\circledR}$ Spectrum microplate; Thermo Labsystems, Vantaa, Finland), and referenced to a standard curve of CS over a range of concentrations from 0.01 to $2.5 \mathrm{nmol} / \mathrm{mL}$. All experiments were conducted in quadruplicate.

\section{Water content measurements}

For water content measurements, the samples were first dried to a constant weight $\left(W_{\mathrm{i}}\right)$ in vacuo and were then immersed in $\mathrm{BSS}$ at $34^{\circ} \mathrm{C}$ (physiological temperature of the cornea) with reciprocal shaking ( $50 \mathrm{rpm}$ ) in a thermostatically controlled water bath. After 4 hours, the swollen membrane scaffolds were weighed $\left(W_{\mathrm{s}}\right)$, and the equilibrium water content $(\%)$ of the test sample was defined by $\left(\left(W_{\mathrm{s}}-W_{\mathrm{i}}\right) / W_{\mathrm{s}}\right) \times 100$, as described previously. ${ }^{17}$ Results were averaged on six independent runs.

\section{Light transmission measurements}

After equilibrium swelling was reached, each sample was placed in a cell in the middle of the custom-built holder. The optical transmittance of the membranes was measured using the ultraviolet-visible spectrophotometer, operating in a spectral range of 400-700 nm. ${ }^{18}$ During spectrometry of 
scaffolds, the reference sample is the holder only, and the test sample consists of the holder with the membrane in place.

\section{Mechanical tests}

The uniaxial tensile tests were used to characterize the mechanical properties of various membrane scaffolds. ${ }^{19}$ Each sample was immersed in BSS for 4 hours to reach the fully swollen state. Subsequently, wet membranes under pressure were cut with a suitable mold to prepare dumbbell-shaped specimens. The gauge length of the specimens was $10 \mathrm{~mm}$ and the width was $5 \mathrm{~mm}$. All measurements were performed at $25^{\circ} \mathrm{C}$ and a relative humidity of $50 \%$ using an Instron universal testing machine (Mini 44; Instron, Canton, MA). The crosshead speed was set at $1 \mathrm{~mm}$ per minute. Young's modulus was determined from load-displacement curves. Results were averaged on eight independent runs.

\section{In vitro degradation tests}

To measure the extent of degradation, each sample was first dried to a constant weight $\left(W_{\mathrm{i}}\right)$ in vacuo and was then immersed in $1 \mathrm{~mL}$ of BSS containing collagenase $12 \mu \mathrm{g}$ at $34^{\circ} \mathrm{C}$. Degradation medium was replaced weekly with fresh buffer solution containing the same concentration of enzyme. At predetermined time intervals, the degraded membranes were collected and further dried in vacuo. The dry weight of scaffolds after degradation $\left(W_{\mathrm{d}}\right)$ was determined and the percentage of weight remaining was calculated as $\left(W_{\mathrm{d}} / W_{\mathrm{i}}\right) \times 100$. Results were averaged on five independent runs.

\section{Glucose permeation studies}

Glucose permeation studies were performed at $34^{\circ} \mathrm{C}$ using a horizontal glass diffusion cell (PermeGear, Inc, Hellertown, PA), having two stirred chambers with sampling ports. The donor chamber was filled with a $50 \mathrm{mg} / \mathrm{mL}$ glucose solution in BSS ( $3 \mathrm{~mL})$ and the receptor chamber was filled with BSS $(3 \mathrm{~mL})$. After immersion in BSS until equilibrium swelling, the membranes were placed between the two chambers. During the measurements, all solutions were stirred continuously to provide uniform solute distribution and to reduce the boundary layer of glucose. After 12 hours, the receptor chamber was sampled and analyzed using a glucose assay kit (Sigma-Aldrich). ${ }^{8}$ Photometric readings at $540 \mathrm{~nm}$ were measured with a spectrophotometer (Thermo Scientific) and compared with a standard curve of known glucose concentrations. Results were averaged on five independent runs.

\section{Isolation and culture of rabbit corneal keratocytes}

Twelve adult male New Zealand white rabbits (National Laboratory Animal Breeding and Research Center, Taipei, Taiwan, Republic of China) weighing 2.5-3.0 kg were used for this study. All animal procedures were approved by the Institutional Review Board and were performed in accordance with the ARVO (Association for Research in Vision and Ophthalmology) Statement for the Use of Animals in Ophthalmic and Vision Research. For the isolation of stromal keratocytes, each cornea was exposed to Medium 199 and $50 \mu \mathrm{g} / \mathrm{mL}$ of gentamicin. Under a dissecting microscope (Leica, Wetzlar, Germany), Descemet's membrane with the attached endothelium was aseptically stripped from the stroma. ${ }^{20}$ The remaining stroma with epithelium was incubated in $5 \mathrm{mg} / \mathrm{mL}$ of dispase II at $4^{\circ} \mathrm{C}$ overnight. ${ }^{21}$ Loose epithelial sheets were removed, and stromal discs were cut into small pieces and digested using $4 \mathrm{mg} / \mathrm{mL}$ of collagenase I for 24 hours at $37^{\circ} \mathrm{C}$. The keratocytes were mechanically dissociated into single cells, and a cell pellet was collected via centrifugation (1000 rpm, $25^{\circ} \mathrm{C}, 5$ minutes). Thereafter, rabbit corneal keratocytes ( $\mathrm{RCKs}$ ) were resuspended and maintained in regular culture medium consisting of DMEM/ $\mathrm{F} 12,10 \% \mathrm{FBS}$, and 1\% A/A solution. Cultures were incubated in a humidified atmosphere of $5 \%$ carbon dioxide $\left(\mathrm{CO}_{2}\right)$ at $37^{\circ} \mathrm{C}$. The medium was changed every other day. Confluent cell layers were subcultured by treating with trypsin-ethylenediaminetetraacetic acid for 2 minutes and seeded at a 1:4 split ratio. Only third-passage RCKs were used for this study.

\section{In vitro biocompatibility studies}

The procedure for the in vitro biocompatibility evaluation of the membrane scaffolds conducted was adapted from the ISO10993-5 standard test method. ${ }^{22}$ The material samples were sterilized in a $70 \%$ ethanol solution overnight and were thoroughly rinsed in sterilized PBS. A single extract of the test article was prepared using regular growth medium containing DMEM/F12, 10\% FBS, and 1\% A/A solution. The extracts were obtained by incubation of the sterilized materials with culture medium at $37^{\circ} \mathrm{C}$ for 24 hours, with an extraction ratio of $0.2 \mathrm{~g} / \mathrm{mL}$. Each test extract was then placed onto RCK cultures with a seeding density of $5 \times 10^{4}$ cells/well, and maintained at $37^{\circ} \mathrm{C}$ in the presence of $5 \% \mathrm{CO}_{2}$ for 48 hours. The cells in regular growth medium without contacting material samples served as control groups.

Cell morphology was observed by phase contrast microscopy (Nikon Instruments, Inc, Melville, NY). 
Proinflammatory cytokine interleukin-6 (IL-6) expression was detected at messenger RNA levels. ${ }^{23}$ Total RNA was isolated from cells with TRIzol reagent according to the manufacturer's guidelines. Reverse transcription of the extracted RNA $(1 \mu \mathrm{g})$ was performed using ImProm-II (Promega, Madison, WI) and Oligo(dT) ${ }_{15}$ Primer (Promega). The primers used to amplify the rabbit IL-6 complementary DNA (cDNA) were 5'-AAGAAAACACCAGGGTCAGCAT-3' (sense) and 5'-CTTGAGGGTGGCTTCTTCATTC-3' (antisense); those used to amplify the internal control cDNA, glyceraldehyde-3-phosphate dehydrogenase (GAPDH), were 5'-TTGCCCTCAATGACCACTTTG-3' (sense) and 5'-TTACTCCTTGGAGGCCATGTG-3' (antisense). Quantitative real-time reverse transcription polymerase chain reaction was performed on a Light $\mathrm{Cycler}^{\circledR}$ instrument (Roche Diagnostics) according to the manufacturer's instructions and with Light Cycler FastStart ${ }^{\circledR}$ DNA Master SYBR ${ }^{\circledR}$ Green I reagent (Roche Diagnostics). Each sample was determined in triplicate and the results for IL-6 were normalized to the level of GAPDH messenger RNA.

\section{Cell culture studies}

After attachment of RCKs $\left(3.5 \times 10^{4}\right.$ cells/scaffold $)$ onto the sterilized membrane scaffolds, the samples were washed three times with PBS to remove nonattached cells. The cell-polymer constructs were immediately transferred to a new culture well, and the medium was replaced with fresh growth medium. After $1-5$ days of incubation at $37^{\circ} \mathrm{C}$, the proliferation of the cells was evaluated using the CellTiter $96{ }^{\circledR}$ AQueous Non-Radioactive Cell Proliferation Assay (methanethiosulfonate) (Promega), in which the methanethiosulfonate tetrazolium compound is bioreduced by cells to form a water-soluble colored formazan. ${ }^{24}$ The amount of colored product is proportional to the number of metabolically active cells. The combined methanethiosulfonate/ phenazine methosulfate $(20: 1)$ reagent $(100 \mu \mathrm{L})$ was added to each well of the 24-well plate, and incubated for 3 hours at $37^{\circ} \mathrm{C}$ in a $\mathrm{CO}_{2}$ incubator. The data of absorbance readings at $490 \mathrm{~nm}$ were measured using the Multiskan ${ }^{\circledR}$ Spectrum microplate spectrophotometer (Thermo Labsystems), and referenced to a standard curve of absorbance versus cell number as determined by hemacytometer. All experiments were carried out in quadruplicate.

After RCK cultivation on various scaffolds for 1, 3, and 5 days, the supernatants were respectively collected for analyses of collagen and GAG contents. Blank experiments (culture medium exposed to the cell-free scaffolds) were conducted simultaneously for correction of results. The amount of hydroxyproline, which is an amino acid marker of collagen, was determined with some modifications of the protocol used for quantification of hydroxyproline in aqueous humor. ${ }^{8}$ Briefly, after the addition of Ehrlich's aldehyde reagent to each sample, the absorbance was read at $550 \mathrm{~nm}$ by using a spectrophotometer (Thermo Labsystems) and was compared with a standard calibration curve to quantify the amount of hydroxyproline. Colorimetric assay with DMMB reagent was used to determine the GAG content, as described earlier. All experiments were conducted in triplicate.

Additionally, the constructs prepared from 5 days' cultivation of the RCKs on GCS000 and GCS025 samples were further processed for SEM observations. ${ }^{25}$ Evaluations of cell-free scaffolds were conducted simultaneously for comparison. In brief, the samples were fixed with $2 \%$ glutaraldehyde in $0.1 \mathrm{~mol} / \mathrm{L}$ of cacodylic acid buffer ( $\mathrm{pH} 7.4$ ), post fixed in $1 \%$ osmium tetroxide, and dehydrated in a graded series of ethanol solutions. The dried specimens were then sputter coated with gold before examination under scanning electron microscope.

Quantitative real-time reverse transcription polymerase chain reaction studies were performed according to the method described for the in vitro biocompatibility studies. The sequences of the primer pairs for rabbit keratocan were 5'-CTCACGTGGCTTTGATGTGT-3', (sense) and 5'-GACCTTTGTGAGGCGATTGT-3' (antisense); the primers used to amplify the rabbit biglycan cDNA were 5'-CGGGAGCTTCATCTAGACAACA-3' (sense) and 5'-TCGTTGACACCCACCTTGGT-3' (antisense). Each sample was determined in triplicate, and the gene expression results were normalized to the expression of GAPDH.

\section{Statistics}

Results were expressed as mean plus or minus standard deviation. Comparative studies of means were performed using one-way analysis of variance, and $P<0.05$ was considered statistically significant.

\section{Results and discussion Preparation of cross-linked porous gelatin scaffolds}

Freeze-drying is a widely used method to prepare porous gelatin hydrogel scaffolds. ${ }^{26,27}$ In order to enhance the mechanical and degradation-resistant properties of gelatin materials, the porous hydrogel scaffolds were further crosslinked with EDC/NHS (molar ratio of EDC to NHS, 5:1). ${ }^{18}$ The cross-linking index of gelatin hydrogels as a function of treatment time is shown in Figure S1. After reaction 
with cross-linkers for a short period of time (ie, 1.5 hours), the samples had a cross-linking index of $19.4 \% \pm 1.2 \%$. The cross-linking degrees continued to increase, reaching $75.4 \% \pm 1.8 \%$ by 12 hours of treatment, probably because of the gradual formation of new cross-links. Although the number of free amino groups available for cross-linking has been reported to be 30 per 1000, compared with carboxylic acid groups at 120 per 1000 , the number of the consumed carboxylic acid groups is simply 16 per 1000 during carbodiimide cross-linking of collagenous biomaterials. ${ }^{28}$ In the present work, the plateau level was maintained even for long cross-linking times (ie, 96 hours), implying that the NHSactivated carboxylic acid groups of glutamic or aspartic acid residues have already completely reacted with free amino groups of lysine residues to generate amide bonds in gelatin. Therefore, the remaining free amino groups of cross-linked gelatin molecules are subsequently available to react with free carboxyl groups of CS molecules.

\section{Characterizations of CS-modified porous gelatin scaffolds}

Previously, the authors have shown that the pore size and porosity of freeze-dried gelatin hydrogels can be controlled by the heat transfer rate on the nucleation and growth of ice crystals during the freezing process at different temperature levels. ${ }^{8}$ The increase in freezing temperature may lead to the enlarged pore structure of the membranes. In this study, to fabricate the scaffolds with adequate pore size for RCK growth, the gelatin solutions were subjected to freezing at $-80^{\circ} \mathrm{C}$ for 24 hours. Figure $1 \mathrm{~A}$ shows the cross-sectional SEM images of various CS-modified gelatin scaffolds. In all groups, the samples presented a porous three-dimensional structure with thin pore walls. Additionally, similar pore size of around $50 \mu \mathrm{m}$ and porosity of around $25 \%$ were found (Figures S2 and S3), indicating that the modification with $0 \%-1.25 \%(\mathrm{w} / \mathrm{v}) \mathrm{CS}$ does not markedly change the porous structure of EDC/NHS cross-linked gelatin scaffolds. Since the dimension of each corneal stromal keratocyte is 24-35 $\mu \mathrm{m}$ long and 11-14 $\mu \mathrm{m}$ wide, ${ }^{29}$ the results suggest that the porous gelatin scaffolds can provide sufficient space to support cell cultivation.

The energy dispersive X-ray microanalysis mapping technique was employed to investigate the sulfur distribution of the gelatin scaffolds before and after modification with CS. The region enclosed by a square on the SEM images shows the area analyzed with EDS spectra (Figure 1B). The white dots represent the detected sulfur element and the black area indicates the absence of a specific element. Gelatin is a naturally occurring biopolymer that preserves a unique amino acid composition. ${ }^{30}$ As shown in Figure $1 \mathrm{C}$, the carbon, oxygen,
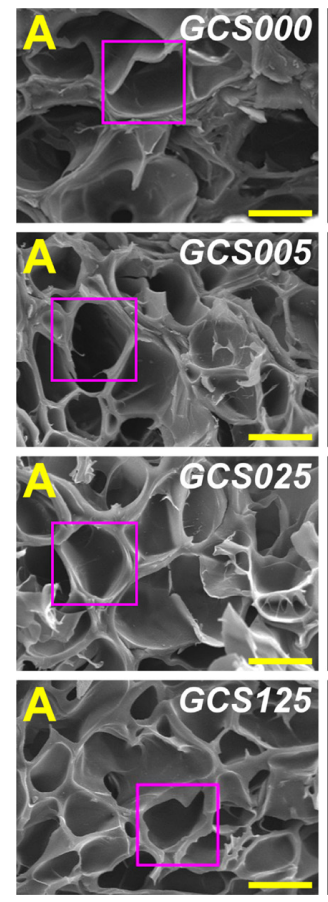
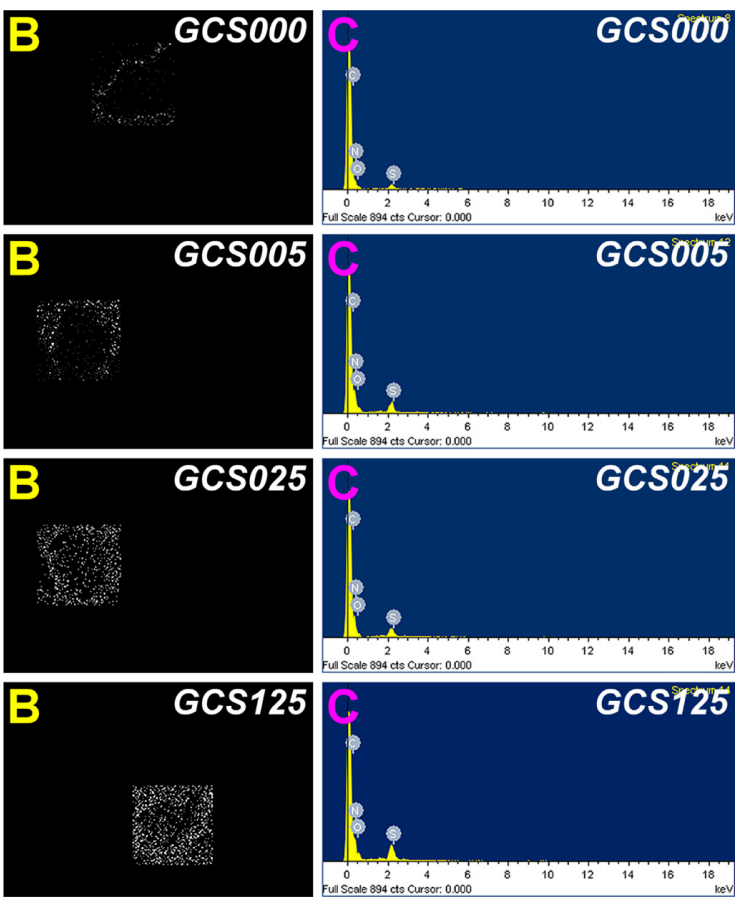

Figure I Scanning electron microscopy/energy dispersive X-ray spectroscopy (EDS) mapping of various porous gelatin scaffolds modified with chondroitin-4-sulfate (GCS000, GCS005, GCS025, and GCSI25): (A) scanning electron microscopy images, (B) EDS mapping of sulfur, and (C) EDS spectrogram.

Notes: Scale bars are $50 \mu \mathrm{m}$; scaffold groups labeled according to chondroitin-4-sulfate concentration used (0\%, 0.05\%, 0.25\%, or I.25\% (w/v)): GCS000, GCS005, GCS025, and GCSI 25 . 
and nitrogen peaks in the EDS spectrogram were noted for all samples. In the GCS000 groups, the S signals were detected because the methionine of gelatin is a sulfur-containing amino acid. Moreover, in the other groups, the porous scaffolds had stronger sulfur peak intensities, suggesting the successful incorporation of CS into the gelatin materials. Although EDS is a semiquantitative characterization tool and its spectrum simply provides a measure of specific elements in the selected area, the present results demonstrate that after modification with CS of high concentration, more white dots appear (Figure 1B).

Representative spectra for the CS and various CS-modified gelatin samples in the wavenumber range of $3700-900 \mathrm{~cm}^{-1}$ are shown in Figure 2A. In the GCS000 groups, the EDC/ NHS-treated gelatin materials had several characteristic
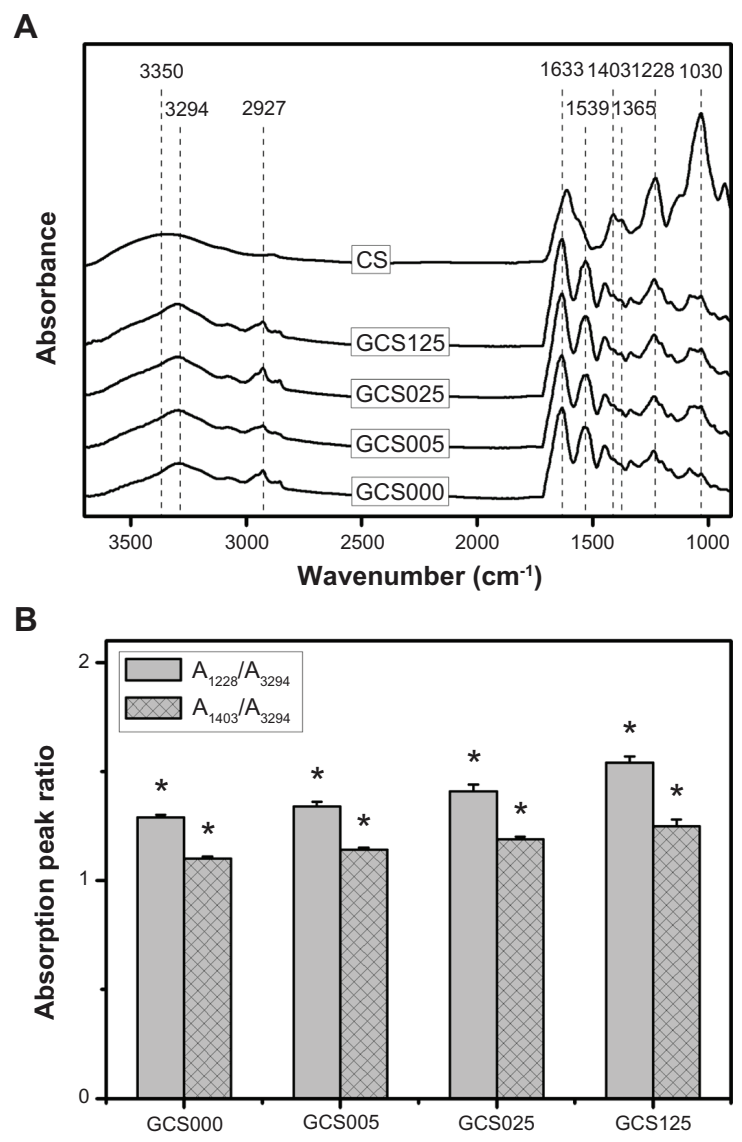

Figure 2 (A) Fourier transform infrared spectroscopy spectra of chondroitin4-sulfate (CS) and the gelatin samples modified with varying concentrations of CS $(0 \%-1.25 \%(\mathrm{w} / \mathrm{v}))$; (B) the absorption peak ratios of the $\mathrm{S}=\mathrm{O}$ stretching to $\mathrm{N}-\mathrm{H}$ stretching bands $\left(\mathrm{A}_{1228} / \mathrm{A}_{3294}\right)$ and $\mathrm{C}-\mathrm{O}$ stretching to $\mathrm{N}-\mathrm{H}$ stretching bands $\left(\mathrm{A}_{1403} / \mathrm{A}_{3294}\right)$ for the gelatin samples modified with varying concentrations of $\mathrm{CS}$ (GCSO00, GCS005, GCS025, and GCSI25).

Notes: Values are mean plus or minus standard deviation $(n=3)$; $* P<0.05$ versus all groups (compared only within $\mathrm{A}_{1228} / \mathrm{A}_{3294}$ or $\mathrm{A}_{1403} / \mathrm{A}_{3294}$ groups); scaffold groups labeled according to CS concentration used $(0 \%, 0.05 \%, 0.25 \%$, or $1.25 \%(\mathrm{w} / \mathrm{v}))$ : GCS000, GCS005, GCS025, and GCSI 25.

Abbreviation: A/A, absorbance/absorbance. absorption bands at $3294 \mathrm{~cm}^{-1}$ (N-H stretching vibration), $2927 \mathrm{~cm}^{-1}$ (C-H stretching vibration), $1633 \mathrm{~cm}^{-1}$ (amide I, $\mathrm{C}=\mathrm{O}$ stretching vibration), $1539 \mathrm{~cm}^{-1}$ (amide II, $\mathrm{N}-\mathrm{H}$ bending vibration), and $1228 \mathrm{~cm}^{-1}$ (amide III, $\mathrm{N}-\mathrm{H}$ bending vibration). For the $\mathrm{CS}$ samples, the spectra exhibited peaks at $3350 \mathrm{~cm}^{-1}$ (-OH stretching vibration), $1030 \mathrm{~cm}^{-1}$ (C-O-C stretching vibration attributed to the saccharide structure), and $1228 \mathrm{~cm}^{-1}$ ( $\mathrm{S}=\mathrm{O}$ stretching vibration attributed to the negatively charged $\mathrm{SO}_{4}{ }^{2-}$ groups of $\mathrm{CS}$ molecules). In addition, the bands at 1403 and $1365 \mathrm{~cm}^{-1}$ were due to the coupling of the $\mathrm{C}-\mathrm{O}$ stretching vibration and $\mathrm{O}-\mathrm{H}$ variable-angle vibration, indicating the existence of the free carboxyl group. ${ }^{31}$ Although the samples GCS005, GCS025, and GCS125 showed a similar pattern of spectra, the peak intensities were dependent on the CS concentration (Figure 2B). In this study, the increased intensity ratios of $\mathrm{A}_{1228} / \mathrm{A}_{3294}$ and $\mathrm{A}_{1403} / \mathrm{A}_{3294}$ are indicative of increased CS signals. When compared with their counterparts treated with $0.05 \% \mathrm{CS}$, the gelatin scaffolds modified with $1.25 \% \mathrm{CS}$ revealed higher intensity $\mathrm{S}=\mathrm{O}$ stretching bands. Despite the possibility that formation of amide bonds between gelatin and CS may involve the consumption of free carboxyl groups in the polysaccharide, the peak intensity at $1403 \mathrm{~cm}^{-1}$ slightly increased with an increase in the feed amount of CS for covalent attachment to gelatin. These findings confirm the presence of varying levels of CS in the porous gelatin scaffolds and further support the observations shown in Figure 1.

During the carbodiimide-mediated modification of gelatin with CS, the formation of amide bonds between the free amino and carboxyl groups of the polypeptide chain may occur because the gelatin is an amphiphilic polyelectrolyte. To avoid the undesirable protein self-cross-linking, in this study, the porous gelatin scaffolds were treated with EDC/NHS for 12 hours prior to reaction with CS for a further 24 hours. The results of ninhydrin assays demonstrated that the number of free amino groups of gelatin does not change following repeated exposure to EDC and NHS in the absence of CS (data not shown). In contrast, under the same coupling conditions in the presence of CS, the number of free amino groups decreased, indicating that the NHS-activated carboxyl groups of mobile CS molecules are able to react with the remaining free amino groups of cross-linked gelatin molecules. The CS content of porous gelatin scaffolds as a function of CS concentration is shown in Figure 3. After modification, the samples from GCS005, GCS025, and GCS125 groups had the CS content of $0.078 \pm 0.004$, $0.112 \pm 0.003$, and $0.149 \pm 0.006 \mathrm{nmol}$ per $10 \mathrm{mg}$ scaffold, respectively. The values revealed significant differences 


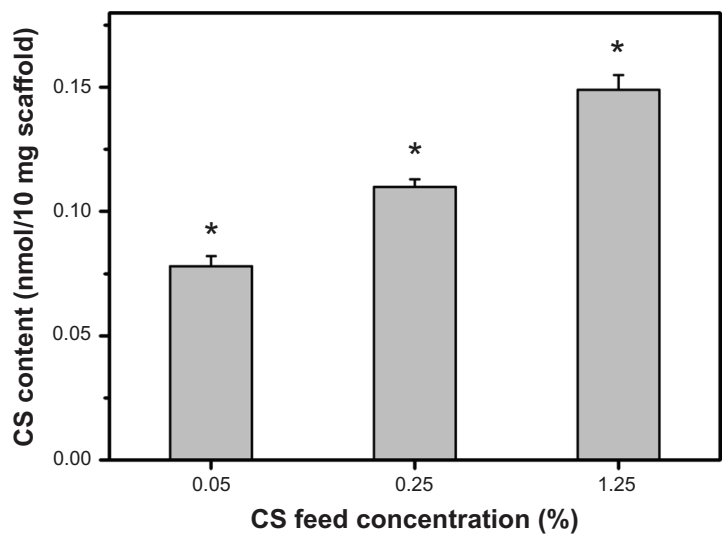

Figure 3 The chondroitin-4-sulfate (CS) content (determined by dimethylmethylene blue assay) of the gelatin scaffolds modified with varying concentrations of CS $(0 \%-1.25 \%(w / v))$.

Notes: Values are mean plus or minus standard deviation $(n=4)$; ${ }^{*} P<0.05$ versus all groups.

between these three groups $(P<0.05)$. Given that the generation of amide bonds between gelatin and CS is affected by the collision frequency of these biomacromolecules, the higher concentration may lead to the covalent incorporation of larger amounts of CS into the porous gelatin scaffolds.

\section{Water content measurements}

Gelatin is known to exhibit rapid dissolution in aqueous environments. In this study, carbodiimide chemistry was applied to treat gelatin matrices to circumvent the constraint. After incubation in BSS at $34^{\circ} \mathrm{C}$ for 4 hours, the EDC/NHS cross-linked porous gelatin scaffolds from GCS000 groups had an equilibrium water content of $65.3 \% \pm 0.8 \%$ (Figure 4 ). It has been documented that the water content of normal cornea is around $76 \%{ }^{32}$ When the hydration levels of

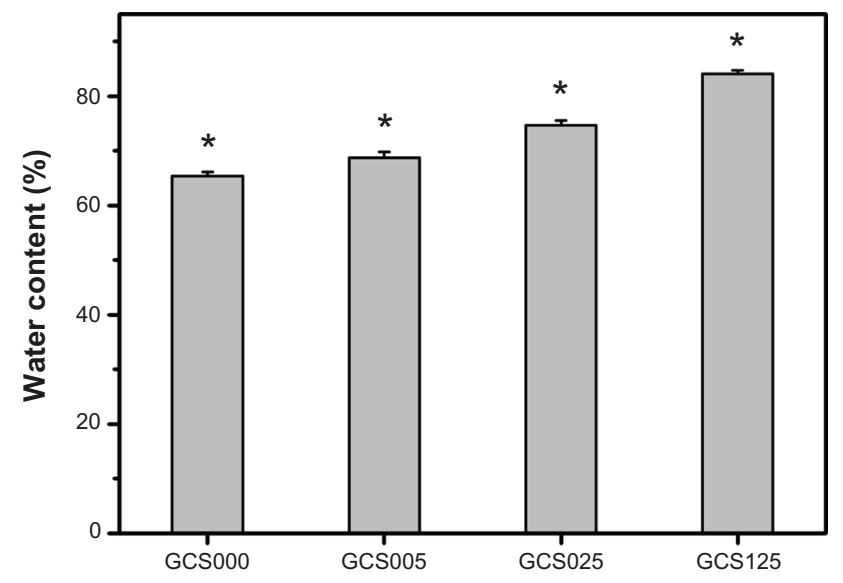

Figure 4 Equilibrium water content of various porous gelatin scaffolds modified with concentrations of chondroitin-4-sulfate (GCS000, GCS005, GCS025, and GCSI25). Notes: Values are mean plus or minus standard deviation $(n=6)$; $* P<0.05$ versus all groups; scaffold groups labeled according to chondroitin-4-sulfate concentration used $(0 \%, 0.05 \%, 0.25 \%$, or I. $25 \%(w / v))$ : GCS000, GCS005, GCS025, and GCSI 25 . cornea exceed $83 \%$, epithelial and/or endothelial damage may occur. ${ }^{33}$ Hence, the scaffold material should be modified by introduction of an optimal amount of CS into the gelatin. The water content in the GCS025 (74.6\% $\pm 0.9 \%)$ groups was significantly higher than that of the GCS005 $(68.7 \% \pm 1.1 \%)$ groups and significantly lower than that of the GCS125 $(84.1 \% \pm 0.6 \%)$ groups $(P<0.05)$.

\section{Light transmission measurements}

The cornea is the transparent circular part of the front of the eyeball that covers the pupil, iris, and anterior chamber. ${ }^{1}$ Figure 5 shows the light transmission through various scaffolds, in the visible light range of 400-700 $\mathrm{nm}$. The sample GCS000 had an average transmittance of $36.1 \%$, which was lower than that reported for human cornea (around 60\%). ${ }^{34}$ Teoh et $\mathrm{al}^{35}$ have demonstrated that the porous structure in ultra high-molecular-weight polyethylene film causes light scattering and reduces the light transmission. This may account for the poor transparency of porous gelatin membranes without CS modification. In contrast, the transmittance values in the GCS025 and GCS125 groups increased to $43.9 \%$ and $48.8 \%$, respectively, suggesting the role of CS in the regulation of material optical properties. Results of the current study support a report by Vrana et $\mathrm{al}^{36}$ showing that the addition of GAG substantially improves the transparency of collagen films.

\section{Mechanical tests}

The mechanical properties of various CS-modified gelatin scaffolds are shown in Figure 6. The Young's modulus was significantly lower in the GCS025 (5.3 $\pm 1.0 \mathrm{MPa})$

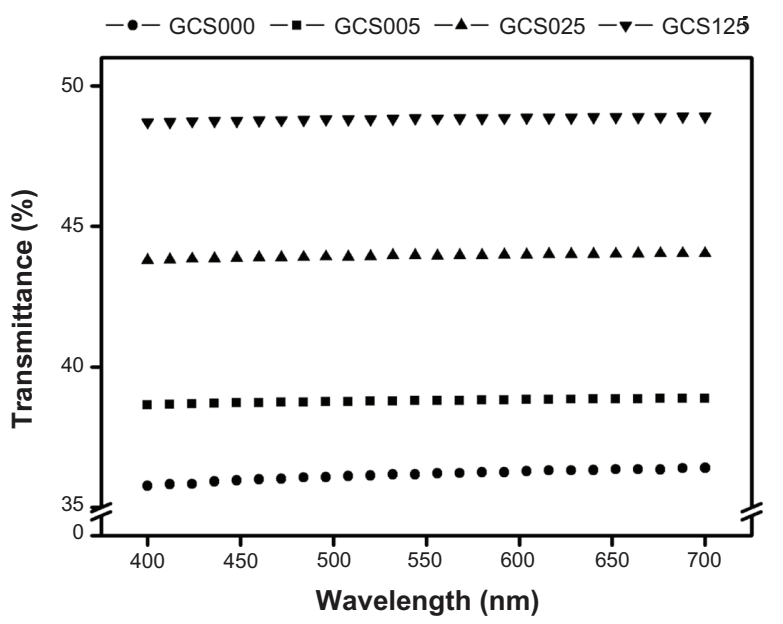

Figure 5 Optical transmittance of various porous gelatin scaffolds (GCS000, GCS005, GCS025, and GCSI25) modified with concentrations of chondroitin-4-sulfate.

Notes: Scaffold groups labeled according to chondroitin-4-sulfate concentration used $(0 \%, 0.05 \%, 0.25 \%$, or $1.25 \%(w / v))$ : GCS000, GCS005, GCS025, and GCSI 25 . 


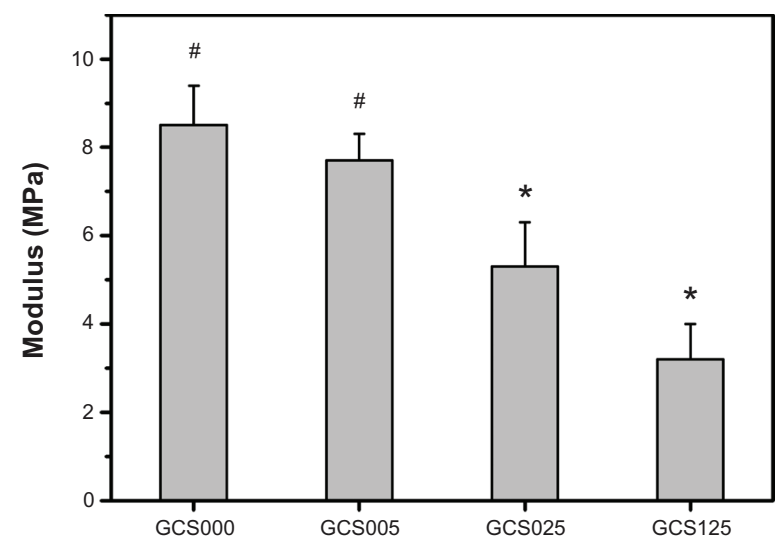

Figure 6 Young's modulus of various porous gelatin scaffolds (GCS000, GCS005, GCS025, and GCSI25) modified with concentrations of chondroitin-4-sulfate.

Notes: Values are mean plus or minus standard deviation $(n=8)$; $* P<0.05$ versus all groups; ${ }^{\# P}<0.05$ versus GCS025 and GCSI 25 groups; scaffold groups labeled according to chondroitin-4-sulfate concentration used $(0 \%, 0.05 \%, 0.25 \%$, or $1.25 \%$ (w/v)): GCS000, GCS005, GCS025, and GCSI 25.

groups than in the GCS005 $(7.7 \pm 0.6 \mathrm{MPa})$ and GCS000 $(8.5 \pm 0.9 \mathrm{MPa})$ groups $(P<0.05)$. The authors' findings suggest that the samples with a CS content $\geq 0.112 \pm 0.003 \mathrm{nmol}$ per $10 \mathrm{mg}$ scaffold exhibit poor mechanical stability. One possible explanation is that the presence of absorbed water has a profound influence on the tensile properties of hydrophilic biomacromolecules. ${ }^{19}$ Although the treatment of gelatin with $1.25 \%$ CS significantly enhances the hydrophilicity and decreases the structural strength, the Young's modulus of these porous scaffolds corresponds to the range of the measured normal corneal tissue values (ie, $0.3-7 \mathrm{MPa}) .{ }^{37}$ The authors have also attempted to perform microscale modification of porous gelatin scaffolds with CS. However, when the CS content is around $1 \mu \mathrm{mol}$ per $10 \mathrm{mg}$ scaffold, the water content is $93.3 \% \pm 0.9 \%$ (far above $76 \%$ ) and the Young's modulus is $0.21 \pm 0.06 \mathrm{MPa}$ (slightly below $0.3 \mathrm{MPa}$ ), indicating that the hydrophilic and mechanical properties of the samples are much different from those of native corneas. Therefore, the present study proposes nanoscale modification of gelatin with CS for potential use as tissue-engineered corneal keratocyte scaffolds.

\section{In vitro degradation tests}

Given that the formation of cross-links can increase the resistance against protease digestion, the in vitro degradation rate of gelatin materials strongly depends on their cross-linking degree. ${ }^{16}$ The percentage of weight remaining for various CS-modified gelatin scaffolds as a function of incubation time is presented in Figure 7. In the GCS000 groups, approximately $20 \%$ of weight loss

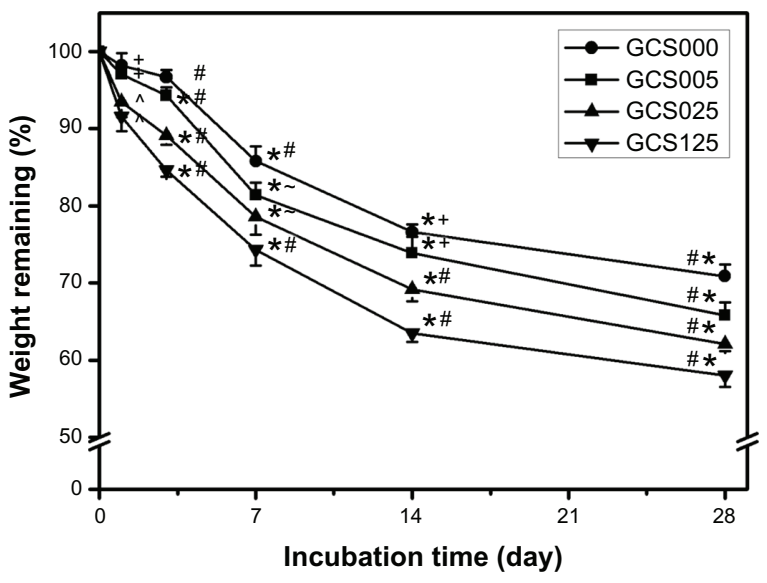

Figure 7 Time course of the percentage of weight remaining for various chondroitin4-sulfate-modified porous gelatin scaffolds (GCS000, GCS005, GCS025, and GCSI 25) after incubation at $34^{\circ} \mathrm{C}$ in a balanced salt solution containing collagenase.

Notes: An asterisk indicates statistically significant differences $(* P<0.05 ; n=5)$ for the mean value of weight remaining compared with value at previous time point: ${ }^{\#} P<0.05$ versus all groups; ${ }^{+} P<0.05$ versus GCS025 and GCSI 25 groups; ${ }^{\wedge} P<0.05$ versus GCS000 and GCS005 groups; - $P<0.05$ versus GCS000 and GCSI 25 groups (compared only within each time point group); scaffold groups labeled according to chondroitin-4-sulfate concentration used $(0 \%, 0.05 \%, 0.25 \%$, or $1.25 \%(\mathrm{w} / \mathrm{v}))$ : GCSO00, GCS005, GCS025, and GCSI 25.

was observed during the period from 1 to 14 days, and the residual membranes slowly degraded with time. A similar trend was also noted for the other three groups. In particular, at each time point, the measured remaining weight showed a significant difference between the GCS005 and GCS125 groups $(P<0.05)$, suggesting that the incorporation of larger CS amounts may accelerate the cleavage of peptide bonds within the triple-helical structure of gelatin. As mentioned, the samples with more CS content had higher water content, thus possibly increasing the access of enzyme to the active sites of the polymer chains and promoting exogenous collagenolytic degradation of scaffold matrices.

\section{Glucose permeation studies}

The concentration of glucose permeated through various CS-modified gelatin scaffolds at $34^{\circ} \mathrm{C}$ for 12 hours is shown in Figure 8. The glucose concentration in the GCS000, GCS005, GCS025, and GCS125 groups was 828.3 \pm 49.4 , $946.1 \pm 55.6,1140.0 \pm 65.0$, and $1341.7 \pm 76.1 \mu \mathrm{mol} / \mathrm{L}$, respectively. There were significant differences among these groups $(P<0.05)$. The present data indicate that an increase in the amount of permeated nutrients is observed with increasing CS concentration. The EDC/NHS cross-linked gelatin hydrogels are macromolecular networks able to absorb large amounts of water without dissolution. In the range $0.1-0.001 \mathrm{~mol} / \mathrm{L}$ of ionic strength, the $\mathrm{pKa}$ of the carboxyl group of CS increases from 3.5 to 5.7. ${ }^{38}$ As a result, a stronger 


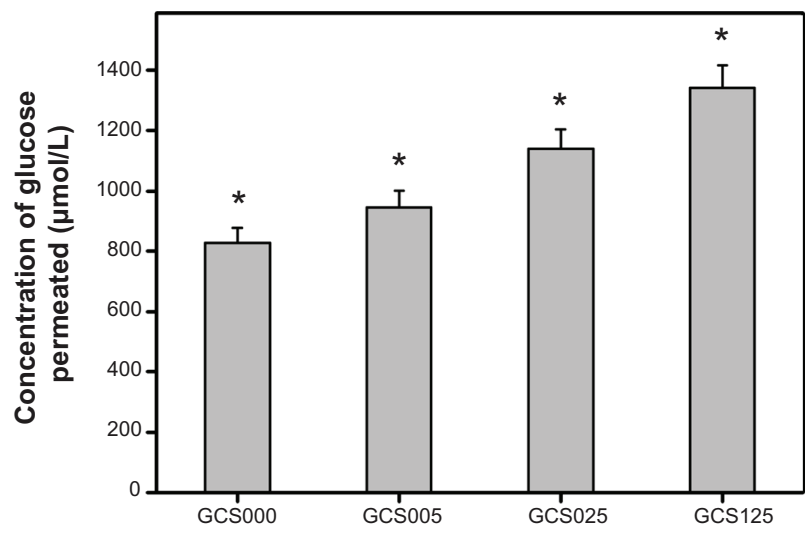

Figure 8 Concentration of glucose permeated through various chondroitin-4sulfate-modified porous gelatin scaffolds (GCS000, GCS005, GCS025, and GCSI25) at $34^{\circ} \mathrm{C}$.

Notes: Values are mean plus or minus standard deviation $(n=5)$; $* P<0.05$ versus all groups; scaffold groups labeled according to chondroitin-4-sulfate concentration used $(0 \%, 0.05 \%, 0.25 \%$, or I. $25 \%$ (w/v)): GCS000, GCS005, GCS025, and GCSI 25 .

electrostatic repulsive force existing between carboxylate ions contributes to the expansion of the biopolymer network structure of sample GCS125, thereby detecting the higher glucose concentration in the receptor chamber under physiological buffer conditions.

\section{In vitro biocompatibility studies}

Representative light microscopic images of RCK cultures photographed after 2 days are shown in Figure 9A. The keratocytes exposed to serum in vitro are known to exhibit a fibroblastic morphology. In this study, all the examined cells in the control groups showed this characteristic feature. Except for the GCS125 groups, the CS-modified gelatin materials of all groups demonstrated similar culture results. The RCKs also appeared healthy and actively proliferated. After the exposure to the sample GCS125, the cells are wider/ flatter and more cuboidal than the control cells.

The proinflammatory gene expression of RCKs exposed to various CS-modified gelatin samples for 2 days is shown in Figure 9B. It was found that the IL-6 expression levels of cells did not differ significantly between the control and experimental groups treated with concentrations of CS ranging from $0 \%$ to $1.25 \%$. The present results indicate that the incubation of RCKs with extract medium conditioned with the test samples has little effect on inflammation. According to the authors' recent reports, the carbodiimide cross-linked gelatin hydrogel has excellent compatibility toward corneal endothelial cells, ${ }^{8}$ iris pigment epithelial cells, ${ }^{39}$ and retinal pigment epithelial cells. ${ }^{14}$ Moreover, GAGs are nonimmunogenic and biodegradable to nontoxic oligosaccharides. ${ }^{40}$ In this study, the RCK cultures contacting with CS-modified
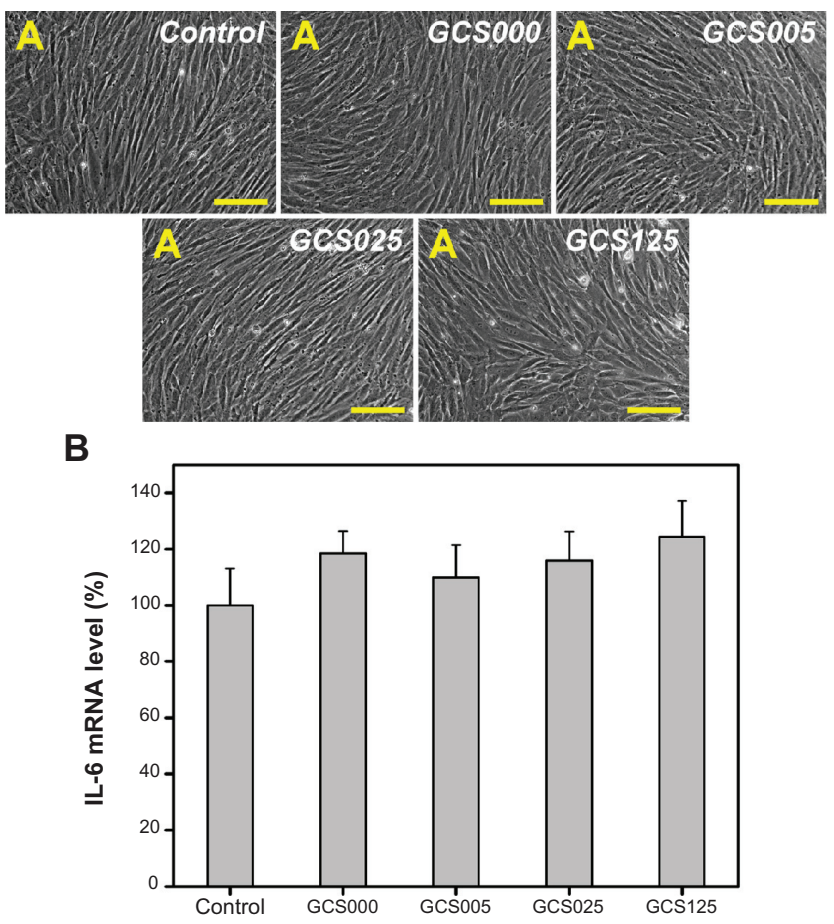

Figure 9 (A) Phase contrast micrographs of rabbit corneal keratocyte cultures incubated for 2 days at $37^{\circ} \mathrm{C}$ with extract medium conditioned with various chondroitin-4-sulfate-modified porous gelatin scaffolds (control, GCS000, GCS005, GCS025, and GCSI25); (B) gene expression of interleukin-6 (IL-6) in rabbit corneal keratocytes incubated with extract medium conditioned with various chondroitin4-sulfate-modified porous gelatin scaffolds for 2 days, measured by real-time reverse transcription polymerase chain reaction.

Notes: Scale bars, $100 \mu \mathrm{m}$; glyceraldehyde-3-phosphate dehydrogenase was used for normalization; data in the experimental groups are percentages relative to that of control groups (without materials); values are mean plus or minus standard deviation $(n=3)$; scaffold groups labeled according to chondroitin-4-sulfate concentration used $(0 \%, 0.05 \%, 0.25 \%$, or $1.25 \%$ (w/v)): GCS000, GCS005, GCS025, and GCSI 25 . Abbreviation: mRNA, messenger RNA.

gelatin materials does not upregulate their expression of IL-6, suggesting good in vitro biocompatibility of the scaffolds.

\section{Cell culture studies}

The results of quantitative analysis for RCK proliferation within various scaffolds are shown in Figure 10. After 1 day of culture, the total cell number in GCS000, GCS005, and GCS025 groups reached about $5 \times 10^{4}$, compared with the initial adherent cell number (ie, $3.5 \times 10^{4}$ ). It has been reported that the doubling time for RCKs is 18 hours. ${ }^{41}$ In the current study, the cultured cells from porous three-dimensional scaffolds displayed a slower proliferation rate. For all the CS-modified gelatin samples, the cell proliferation was significantly increased in a time-dependent manner $(P<0.05)$. Both the gelatin membranes from GCS000 and GCS005 groups did not affect cell proliferation at each time point. During the period of 5 days, the total cell number in GCS000 groups ranged from $5 \times 10^{4}$ to $6 \times 10^{4}$. However, the RCKs on the scaffolds modified with higher 


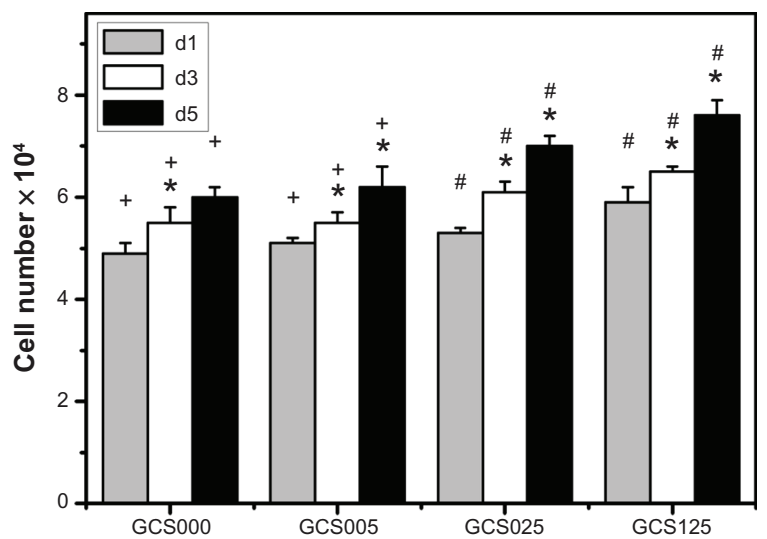

Figure 10 Total cell number on various chondroitin-4-sulfate-modified porous gelatin scaffolds (GCS000, GCS005, GCS025, and GCSI25). after rabbit corneal keratocyte seeding for I, 3 , and 5 days ( $\mathrm{dI}, \mathrm{d} 3$, and $\mathrm{d} 5$, respectively).

Notes: An asterisk indicates statistically significant differences $(* P<0.05 ; n=4)$ for the mean value of total cell number compared with value at previous time point; ${ }^{*} P<0.05$ versus all groups; ${ }^{+} P<0.05$ versus $\mathrm{GCS} 025$ and $\mathrm{GCSI} 25$ groups (compared only within each time point group); scaffold groups labeled according to chondroitin-4-sulfate concentration used $(0 \%, 0.05 \%, 0.25 \%$, or $1.25 \%(w / v))$ : GCS000, GCS005, GCS025, and GCSI 25.

CS concentration (ie, GCS025 and GCS125 groups) showed significantly higher cell numbers $(P<0.05)$. Investigators have performed studies on the biological effects of CS, but the results are inconsistent. Ida et $\mathrm{al}^{42}$ demonstrated that the epidermal growth factor-mediated proliferation of neural stem/progenitor cells was not stimulated by CS. In contrast, Westergren-Thorsson et a ${ }^{43}$ reported that while the L-iduronic acid-containing galactosaminoglycans such as dermatan sulfate could inhibit the human lung fibroblast proliferation in vitro, the galactosaminoglycan not containing L-iduronic acid (ie, CS) effectively stimulated the proliferation of these cells. Zou et a ${ }^{44}$ also demonstrated that continuous supplementation of the culture medium with CS led to a dose-dependent increase in the number of palatal fibroblasts after a 7-day incubation period. The results of the current study indicate that the gelatin materials from GCS025 and GCS125 groups can markedly enhance the proliferative capacity of RCKs.

The total collagen and GAG contents after RCK growth within various scaffolds over the 5-day culture are shown in Figure 11 (A and B, respectively). The level of ECM secretion was elevated in the culture medium with increasing incubation time. At day 5, the amount of total collagen in the GCS000 groups was $13.5 \pm 0.9 \mu \mathrm{g} / 10^{6}$ cells, which was significantly lower than those of the GCS005 (20.7 $\pm 1.2 \mu \mathrm{g} / 10^{6}$ cells), GCS025 (28.2 $\pm 1.5 \mu \mathrm{g} / 10^{6}$ cells), and GCS125 (34.6 $\pm 1.3 \mu \mathrm{g} / 10^{6}$ cells) groups $(P<0.05)$. A similar trend was found for the effect of material composition on the variation in GAG secretion. These findings suggest that the covalent incorporation of larger amounts of
A

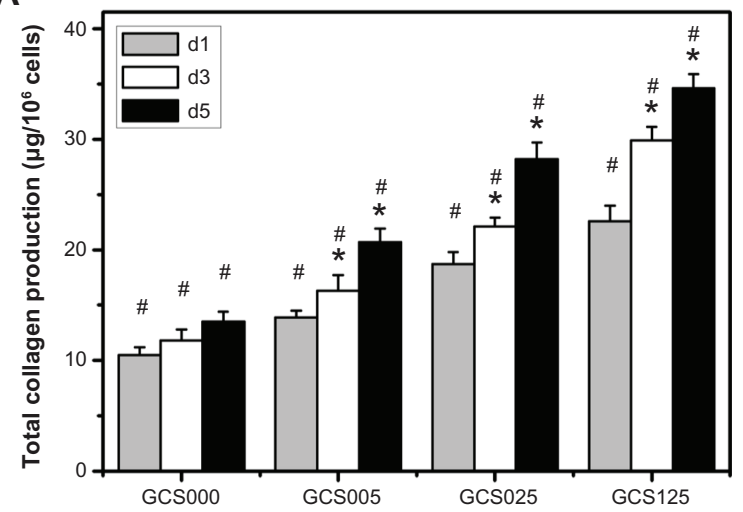

B

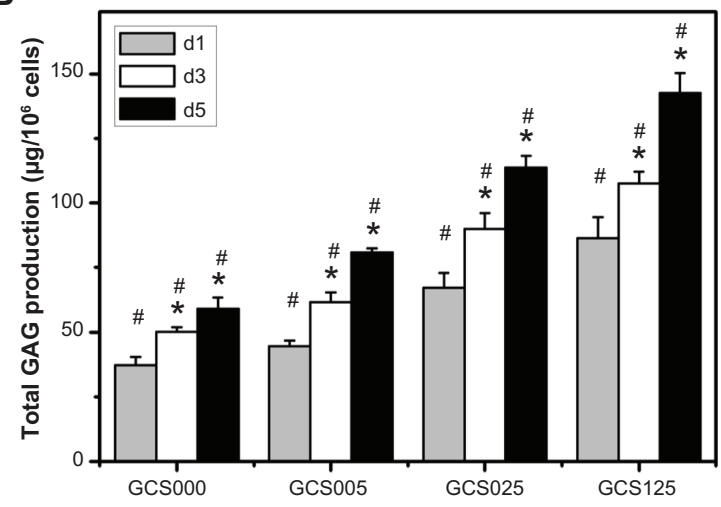

Figure I I Extracellular matrix production capacity of rabbit corneal keratocytes at days I, 3, and 5 (dI, d3, and d5, respectively) after plating on various chondroitin-4sulfate-modified porous gelatin scaffolds (GCS000, GCS005, GCS025, and GCSI25): (A) collagen content and (B) glycosaminoglycan (GAG) content.

Notes: An asterisk indicates statistically significant differences $(* P<0.05 ; n=3)$ for the mean value of extracellular matrix content compared with value at previous time point; $" P<0.05$ versus all groups (compared only within each time point group); scaffold groups labeled according to chondroitin-4-sulfate concentration used $(0 \%$, $0.05 \%, 0.25 \%$, or I. $25 \%(\mathrm{w} / \mathrm{v})$ ): GCS000, GCS005, GCS025, and GCSI 25 .

CS into the porous gelatin scaffolds can effectively expand the biosynthetic capacity of cultured RCKs. In addition to the measurement of the collagen and GAGs in the medium supernatants, the ECM production of RCKs was examined by the direct observation of the cell-biopolymer constructs after 5 days of cultivation (Figure 12A and B). SEM images showed that the cells of the GCS000 groups synthesized and deposited their own ECM components. In contrast, the cultures of the GCS025 groups had more abundant ECM. The cell-free scaffolds from both groups did not contain newly deposited ECM (Figure 12C and D). It has been documented that the biochemical composition of the biomaterial scaffolds plays an important role in the regulation of metabolic parameters of the cells. ${ }^{45}$ Meier and $\mathrm{Hay}^{46}$ reported that the CS proteoglycan had a stimulatory effect on GAG production by corneal epithelial cells. ${ }^{46} \mathrm{~A}$ study from van Susante et al ${ }^{47}$ showed that the collagen-CS scaffold contained significantly more newly synthesized GAGs than in the absence of CS after 

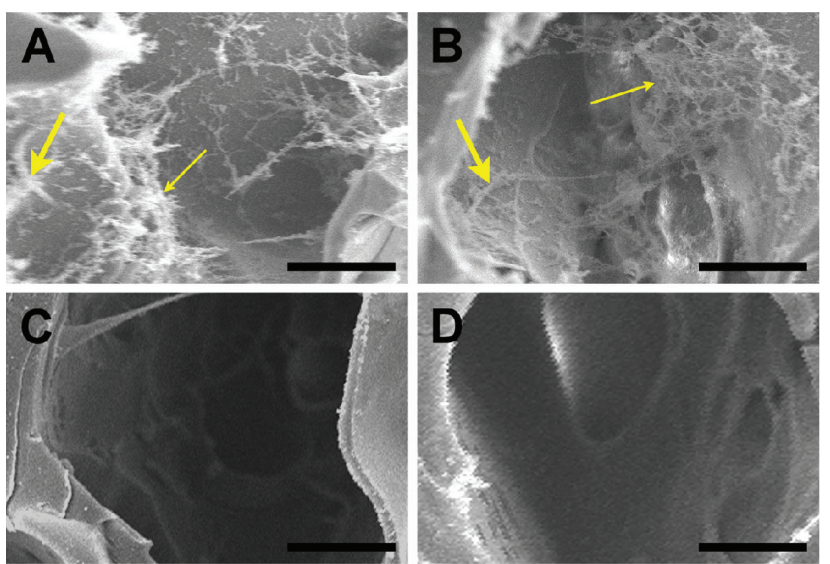

$\mathbf{E}$

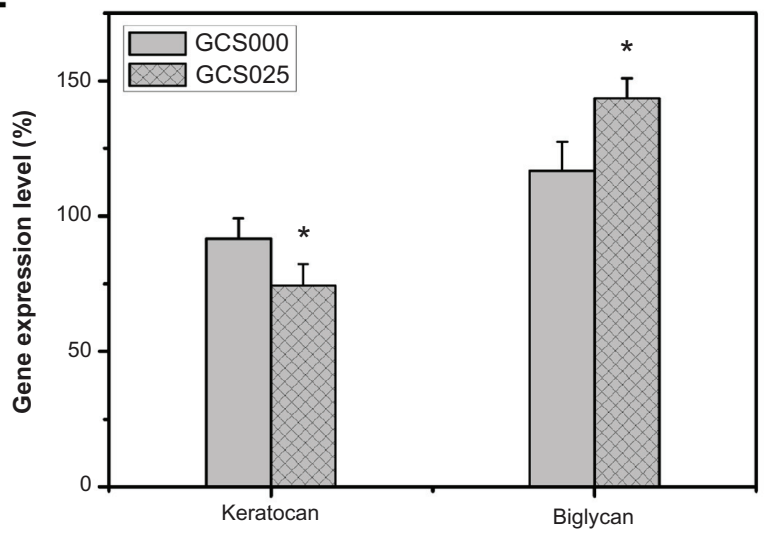

Figure 12 Scanning electron microscopy images of (A and $\mathbf{B}$ ) the constructs prepared from 5 days' cultivation of the rabbit corneal keratocytes on scaffold samples and (C and $\mathbf{D}$ ) the cell-free scaffolds (large arrow indicates cell, fine arrow indicates extracellular matrix). Groups are labeled according to chondroitin-4sulfate concentration used: (A and C) GCS000 (0\% (w/v)) and (B and D) GCS025 $(0.25 \%(w / v))$. (E) Gene expression level of keratocan and biglycan in rabbit corneal keratocytes grown on tissue culture polystyrene and scaffold samples GCS000 and GCS025 for 5 days by real-time reverse transcription polymerase chain reaction.

Notes: Scale bars, $20 \mu \mathrm{m}$; glyceraldehyde-3-phosphate dehydrogenase was used for normalization; data in the experimental groups are percentages relative to that of tissue culture polystyrene groups; an asterisk indicates statistically significant differences $(* P<0.05 ; n=3)$ as compared with the GCS000 groups.

14 days of chondrocyte culture. Results of the present study are compatible with these earlier observations and indicate that the differences in the CS content of porous gelatin scaffolds may have a profound influence on the ECM production capacity of RCKs.

Figure 12E shows the gene expression profiles for two phenotypic markers (keratocan and biglycan). The detected expression level for each gene in the tissue culture polystyrene groups was defined as $100 \%$. After cultivation for 5 days, the RCKs on GCS025 samples showed significantly lower keratocan levels and higher biglycan levels than those of GCS000 groups $(P<0.05)$, indicating that the cell phenotype is not adequately maintained by the incorporation of $\mathrm{CS}$ into the gelatin materials. Vrana et $\mathrm{al}^{48}$ have previously reported the development of a reconstructed cornea from
collagen-CS foams and human cell cultures. The results of their study indicate that even though the keratocytes lose a phenotypic marker, these cells do not differentiate into myofibroblasts during culture within the foams.

\section{Conclusion}

Three-dimensional biomaterial scaffolds have been designed to provide temporary support for cell growth. In this study, nanoscale modification of gelatin with CS was performed to control characteristics in tissue-engineered corneal keratocyte scaffolds. When compared with their counterparts without CS modification, the porous gelatin membranes treated with $0.05 \%-1.25 \%$ CS had higher levels of water content, light transmittance, and amount of permeated nutrients, but had lower Young's modulus and resistance against protease digestion. The hydrophilic and mechanical properties of GCS025 samples were comparable with those of native corneas. Additionally, the scaffolds modified with $0.25 \%$ CS exhibited excellent compatibility toward RCKs and demonstrated enhanced proliferative and biosynthetic capacity of cultured cells. The findings suggest that the gelatin materials with the CS content of $0.112 \pm 0.003 \mathrm{nmol}$ per $10 \mathrm{mg}$ scaffold may hold potential for use in corneal stromal tissue engineering. The validity of the CS-modified porous gelatin scaffolds requires further biological testing, which is currently underway.

\section{Acknowledgments}

This work was supported by grant NSC99-2221-E-182-008 from the National Science Council of the Republic of China and grant CMRPD190431 from Chang Gung Memorial Hospital.

\section{Disclosure}

The authors report no conflicts of interest in this work.

\section{References}

1. Lai JY, Hsiue GH. Functional biomedical polymers for corneal regenerative medicine. React Funct Polym. 2007;67(11):1284-1291.

2. Minami Y, Sugihara H, Oono S. Reconstruction of cornea in three-dimensional collagen gel matrix culture. Invest Ophthalmol Vis Sci. 1993;34(7):2316-2324.

3. Griffith M, Osborne R, Munger R, et al. Functional human corneal equivalents constructed from cell lines. Science. 1999;286(5447):2169-2172.

4. Vrana NE, Builles N, Kocak H, et al. EDC/NHS cross-linked collagen foams as scaffolds for artificial corneal stroma. J Biomater Sci Polym Ed. 2007;18(12):1527-1545.

5. Lu PL, Lai JY, Tabata Y, Hsiue GH. A methodology based on the "anterior chamber of rabbit eyes" model for noninvasively determining the biocompatibility of biomaterials in an immune privileged site. J Biomed Mater Res A. 2008;86(1):108-116. 
6. Hsiue GH, Lai JY, Chen KH, Hsu WM. A novel strategy for corneal endothelial reconstruction with a bioengineered cell sheet. Transplantation. 2006;81(3):473-476.

7. Lai JY, Chen KH, Hsiue GH. Tissue-engineered human corneal endothelial cell sheet transplantation in a rabbit model using functional biomaterials. Transplantation. 2007;84(10):1222-1232.

8. Lai JY, Li YT. Functional assessment of cross-linked porous gelatin hydrogels for bioengineered cell sheet carriers. Biomacromolecules. 2010;11(5):1387-1397.

9. Levick JR. Flow through interstitium and other fibrous matrices. Q J Exp Physiol. 1987;72(4):409-437.

10. Liu Y, Griffith M, Watsky MA, et al. Properties of porcine and recombinant human collagen matrices for optically clear tissue engineering applications. Biomacromolecules. 2006;7(6):1819-1828.

11. Freund DE, McCally RL, Farrell RA, Cristol SM, L'Hernault NL, Edelhauser HF. Ultrastructure in anterior and posterior stroma of perfused human and rabbit corneas: relation to transparency. Invest Ophthalmol Vis Sci. 1995;36(8):1508-1523.

12. Rada JA, Cornuet PK, Hassell JR. Regulation of corneal collagen fibrillogenesis in vitro by corneal proteoglycan (lumican and decorin) core proteins. Exp Eye Res. 1993;56(6):635-648.

13. Kuijpers AJ, Engbers GHM, Meyvis TKL, et al. Combined gelatin-chondroitin sulfate hydrogels for controlled release of cationic antibacterial proteins. Macromolecules. 2000;33(10):3705-3713.

14. Lai JY, Li YT. Evaluation of cross-linked gelatin membranes as delivery carriers for retinal sheets. Mater Sci Eng C. 2010;30(5):677-685.

15. Lai JY, Chen KH, Hsu WM, Lee TH, Lin SY. Multiple elements in the deposits of opacified Hydroview intraocular lens. Am J Ophthalmol. 2005;139(6):1123-1125.

16. Lai JY, Li YT. Influence of cross-linker concentration on the functionality of carbodiimide cross-linked gelatin membranes for retinal sheet carriers. J Biomater Sci Polym Ed. 2011;22(1-3):277-295.

17. Lai JY, Lu PL, Chen KH, Tabata Y, Hsiue GH. Effect of charge and molecular weight on the functionality of gelatin carriers for corneal endothelial cell therapy. Biomacromolecules. 2006;7(6):1836-1844.

18. Ma DHK, Lai JY, Cheng HY, Tsai CC, Yeh LK. Carbodiimide crosslinked amniotic membranes for cultivation of limbal epithelial cells. Biomaterials. 2010;31(25):6647-6658.

19. Lai JY, Lin PK, Hsiue GH, Cheng HY, Huang SJ, Li YT. Low Bloom strength gelatin as a carrier for potential use in retinal sheet encapsulation and transplantation. Biomacromolecules. 2009;10(2):310-319.

20. Lai JY, Chen KH, Hsu WM, Hsiue GH, Lee YH. Bioengineered human corneal endothelium for transplantation. Arch Ophthalmol. 2006; 124(10):1441-1448.

21. Yoshida S, Shimmura S, Shimazaki J, Shinozaki N, Tsubota K. Serumfree spheroid culture of mouse corneal keratocytes. Invest Ophthalmol Vis Sci. 2005;46(5):1653-1658.

22. Kotzar G, Freas M, Abel P, et al. Evaluation of MEMS materials of construction for implantable medical devices. Biomaterials. 2002;23(13): 2737-2750.

23. Lai JY. The role of Bloom index of gelatin on the interaction with retinal pigment epithelial cells. Int J Mol Sci. 2009;10(8):3442-3456.

24. Lu PL, Lai JY, Ma DHK, Hsiue GH. Carbodiimide cross-linked hyaluronic acid hydrogels as cell sheet delivery vehicles: characterization and interaction with corneal endothelial cells. J Biomater Sci Polym Ed. 2008;19(1):1-18.

25. Lai JY, Ma DHK, Cheng HY, et al. Ocular biocompatibility of carbodiimide cross-linked hyaluronic acid hydrogels for cell sheet delivery carriers. J Biomater Sci Polym Ed. 2010;21(3):359-376.

26. Kang HW, Tabata Y, Ikada Y. Fabrication of porous gelatin scaffolds for tissue engineering. Biomaterials. 1999;20(14):1339-1344.

27. Van Vlierberghe S, Cnudde V, Dubruel P, et al. Porous gelatin hydrogels: 1 . Cryogenic formation and structure analysis. Biomacromolecules. 2007;8(2):331-337.
28. Duan X, Sheardown H. Crosslinking of collagen with dendrimers. J Biomed Mater Res A. 2005;75(3):510-518.

29. Doughty MJ, Seabert W, Bergmanson JPG, Blocker Y. A descriptive and quantitative study of the keratocytes of the corneal stroma of albino rabbits using transmission electron microscopy. Tissue Cell. 2001;33(4): 408-422.

30. Hsiue GH, Lai JY, Lin PK. Absorbable sandwich-like membrane for retinal-sheet transplantation. J Biomed Mater Res. 2002;61(1):19-25.

31. Sui W, Huang L, Wang J, Bo Q. Preparation and properties of chitosan chondroitin sulfate complex microcapsules. Colloid Surf B Biointerfaces. 2008;65(1):69-73.

32. Leonard DW, Meek KM. Refractive indices of the collagen fibrils and extrafibrillar material of the corneal stroma. Biophys J. 1997;72(3): 1382-1387.

33. Monti D, Chetoni P, Burgalassi S, Najarro M, Saettone MF. Increased corneal hydration induced by potential ocular penetration enhancers: assessment by differential scanning calorimetry (DSC) and by desiccation. Int J Pharm. 2002;232(1-2):139-147.

34. Rafat M, Li F, Fagerholm P, et al. PEG-stabilized carbodiimide crosslinked collagen-chitosan hydrogels for corneal tissue engineering. Biomaterials. 2008;29(29):3960-3972.

35. Teoh SH, Tang ZG, Ramakrishna S. Development of thin elastomeric composite membranes for biomedical applications. J Mater Sci Mater Med. 1999;10(6):343-352.

36. Vrana NE, Elsheikh A, Builles N, Damour O, Hasirci V. Effect of human corneal keratocytes and retinal pigment epithelial cells on the mechanical properties of micropatterned collagen films. Biomaterials. 2007;28(29):4303-4310.

37. Jayasuriya AC, Scheinbeim JI, Lubkin V, Bennett G, Kramer P. Piezoelectric and mechanical properties in bovine cornea. J Biomed Mater Res A. 2003;66(2):260-265.

38. Scordilis-Kelley C, Osteryoung JG. Voltammetric studies of counterion transport in solutions of chondroitin sulfate. JPhys Chem. 1996;100(2): 797-804.

39. Lai JY. Biocompatibility of chemically cross-linked gelatin hydrogels for ophthalmic use. J Mater Sci Mater Med. 2010;21(6):1899-1911.

40. Malafaya PB, Silva GA, Reis RL. Natural-origin polymers as carriers and scaffolds for biomolecules and cell delivery in tissue engineering applications. Adv Drug Deliv Rev. 2007;59(4-5):207-233.

41. Cook SD, Aitken DA, Brown SM. Growth and characterization of rabbit corneal cells in vitro. Graefes Arch Clin Exp Ophthalmol. 1987;225(5): 351-356.

42. Ida M, Shuo T, Hirano K, et al. Identification and functions of chondroitin sulfate in the milieu of neural stem cells. J Biol Chem. 2006; 281(9):5982-5991.

43. Westergren-Thorsson G, Persson S, Isaksson A, Önnervik PO, Malmström A, Fransson LA. L-iduronate-rich glycosaminoglycans inhibit growth of normal fibroblasts independently of serum or added growth factors. Exp Cell Res. 1993;206(1):93-99.

44. Zou XH, Foong WC, Cao T, Bay BH, Ouyang HW, Yip GW. Chondroitin sulfate in palatal wound healing. $J$ Dent Res. 2004;83(11):880-885.

45. Nehrer S, Breinan HA, Ramappa A, et al. Matrix collagen type and pore size influence behaviour of seeded canine chondrocytes. Biomaterials. 1997;18(11):769-776.

46. Meier S, Hay ED. Stimulation of extracellular matrix synthesis in the developing cornea by glycosaminoglycans. Proc Natl Acad Sci U S A. 1974;71(6):2310-2313.

47. Van Susante JLC, Pieper J, Buma P, et al. Linkage of chondroitinsulfate to type I collagen scaffolds stimulates the bioactivity of seeded chondrocytes in vitro. Biomaterials. 2001;22(17):2359-2369.

48. Vrana NE, Builles N, Justin V, et al. Development of a reconstructed cornea from collagen-chondroitin sulfate foams and human cell cultures. Invest Ophthalmol Vis Sci. 2008;49(12):5325-5331. 


\section{Supplementary figures}

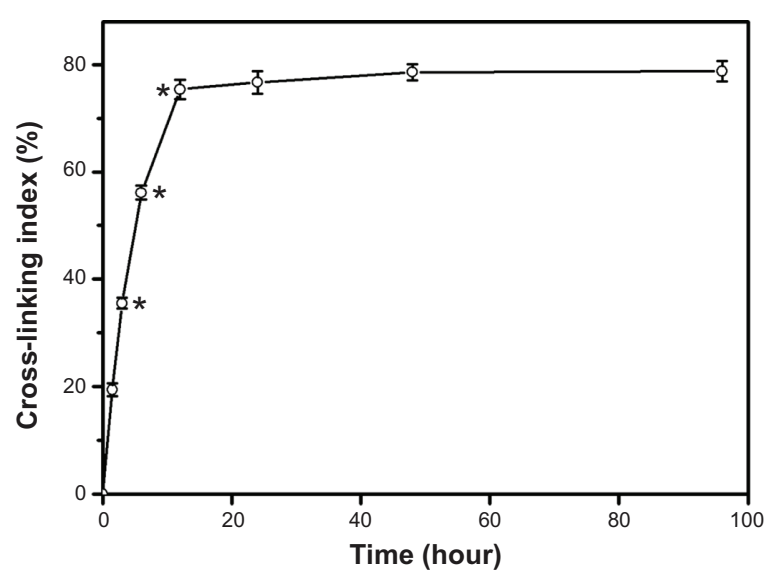

Figure SI Cross-linking index of porous gelatin scaffolds treated with I-ethyl-3(3-dimethyl aminopropyl) carbodiimide hydrochloride/ $\mathrm{N}$-hydroxysuccinimide as a function of cross-linking time.

Notes: An asterisk indicates statistically significant differences $(* P<0.05 ; n=5)$ for the mean value of cross-linking index compared with the value at the previous time point. Abbreviations: EDC, I-ethyl-3-(3-dimethyl aminopropyl) carbodiimide hydrochloride; NHS, N-hydroxysuccinimide.

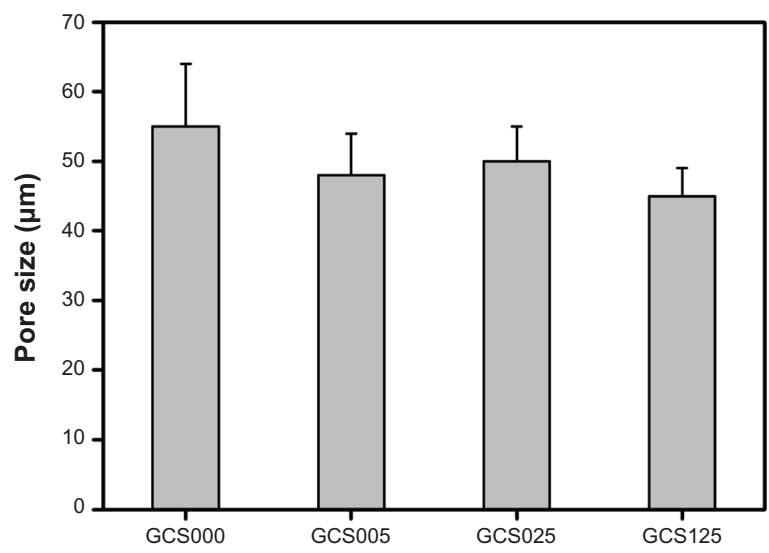

Figure S2 Pore size of various porous gelatin scaffolds modified with chondroitin4-sulfate.

Notes: Values are mean plus or minus standard deviation $(n=3)$; scaffold groups labeled according to chondroitin-4-sulfate concentration used $(0 \%, 0.05 \%, 0.25 \%$, or I.25\% (w/v)): GCS000, GCS005, GCS025, and GCSI 25 .

Abbreviation: CS, chondroitin-4-sulfate.

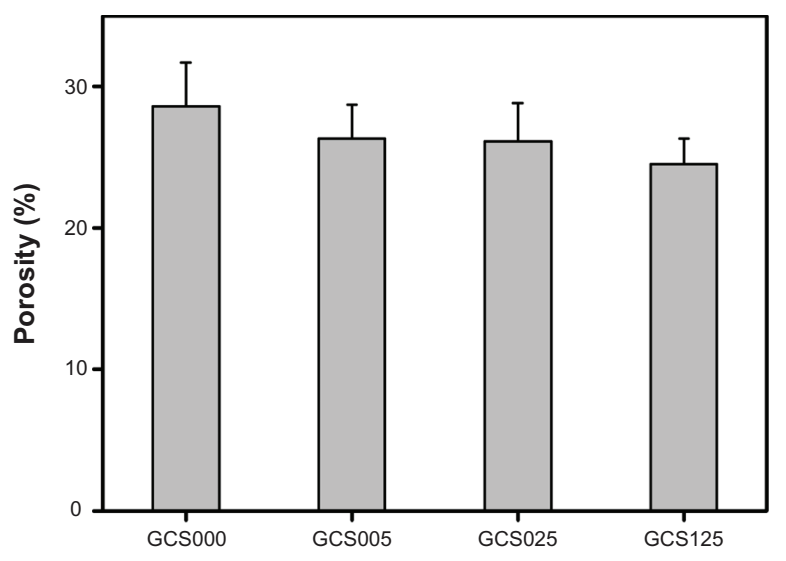

Figure S3 Porosity of various porous gelatin scaffolds modified with chondroitin4-sulfate.

Notes: Values are mean plus or minus standard deviation $(n=5)$; scaffold groups labeled according to chondroitin-4-sulfate concentration used $(0 \%, 0.05 \%, 0.25 \%$, or I.25\% (w/v)): GCS000, GCS005, GCS025, and GCSI25.

Abbreviation: CS, chondroitin-4-sulfate.
International Journal of Nanomedicine

\section{Publish your work in this journal}

The International Journal of Nanomedicine is an international, peerreviewed journal focusing on the application of nanotechnology in diagnostics, therapeutics, and drug delivery systems throughout the biomedical field. This journal is indexed on PubMed Central, MedLine, CAS, SciSearch ${ }^{\circledR}$, Current Contents ${ }^{\circledR} /$ Clinical Medicine,

\section{Dovepress}

Journal Citation Reports/Science Edition, EMBase, Scopus and the Elsevier Bibliographic databases. The manuscript management system is completely online and includes a very quick and fair peer-review system, which is all easy to use. Visit http://www.dovepress.com/ testimonials.php to read real quotes from published authors. 